\title{
ADOLESCENT ADJUSTMENT AND CULTURAL SELF-EFFICACY
}

\author{
Nadia Rania, Paola Cardinali, Chiara Cifatte, Laura Migliorini \\ University of Genoa, Italy \\ E-mail: nadia.rania@unige.it, paola.cardinali@unige.it, \\ chiara.cifatte@unige.it, laura.migliorini@unige.it,
}

\begin{abstract}
Several studies have investigated the conditions for adolescents' adjustment in multicultural contexts. Selfesteem is commonly considered as an index of well-being and of the psychological adjustment of adolescents. Literature on self-esteem maintains that a good level of self-esteem depends on the quality of the subject's intimate relations with family and friends. In a globalized world the personal and relational impact of the management of cross-cultural contacts with the majority and minority groups is becoming increasingly relevant. This study explores the relationship between the constructs of support, self-esteem, well-being and cultural self-efficacy. The research project used a quantitative methodology through the administration of a self-report questionnaire. There were 312 participants, with a mean age of 15 years (20.5\% immigrants). The results show that young immigrants have higher levels of cultural self-efficacy than Italian adolescents. However, in Italian adolescents, cultural self-efficacy correlates with family support. Italians who choose not only Italian friends but also foreign friends have higher levels of cultural self-efficacy. Opportunities for deeper investigation of cultural self-efficacy in the social context are discussed.
\end{abstract}

Key words: adjustment, adolescents, cultural self-efficacy, immigrants, well-being.

\section{Introduction}

The increasingly multi-ethnic character that the Italian context is assuming justifies social psychologists' interest in the dynamics, psychological characteristics and social networks through which people construct their friendships. The psychological consequences of migration in adolescence depend on a variety of individual, social and cultural factors (Scott, \& Scott, 1989; Beiser, 1990; Mirsky, 1997): several studies consider immigrant adolescents as a high-risk group for psychological distress (Walsh, Shulman, \& Maurer, 2008); others were unsuccessful in finding greater psychological distress among immigrant adolescents than among native peers (Klimidis, Stuart, Minas, \& Ata, 1994). During adolescence group identity becomes a dominant theme, because young people desire to belong to a valued social group (Kroger, 2000) and build a positive social identity (Tajfel, \& Turner, 1979) which contributes to a person's self-concept, self-esteem and the ability to cope with developmental problems (Palmonari, Pombeni, \& Kirchler, 1990). 
The school context provides adolescents with the occasion to mix with people from different social and cultural backgrounds: this condition gives an opportunity to select friends according to affinities and similarities, with both positive and negative results (Sabatier, 2008). In reality, mixing ethnic majority and ethnic minority adolescents in school classes does not always reduce negative intergroup attitudes, so it is necessary to consider optimal conditions related to less negative attitudes: equal status, cooperation, common goals and institutional support (Allport, 1954; Pettigrew, 1997). For ethnic majority adolescents, the opportunities for intergroup friendships in class (Vervoort, Sholte, $\&$ Scheepers, 2011) are insufficient to reduce negative out-group attitudes if there are not the optimal conditions proposed by contact theory: only if these conditions are satisfied does intercultural contact in class relate to less negative out-group attitudes, less intergroup anxiety and more self-disclosure (Turner, Voci, \& Hewstone, 2007).

The acquisition of social skills among adolescents is essential to the task of establishing supportive social networks. Self-esteem is commonly considered as an index of well-being and adolescents' psychological adjustment, and the literature supports the view that high-quality friendships are related to higher self-esteem. According to Vervoort and colleagues (2011), self-esteem may be related to higher levels of ethnic identity and more positive in-group attitudes; however, this relation between self-esteem and ethnic identity is significant only for adolescents for whom ethnicity is salient (Phinney, 1991).

Successful relationships are basic to successful living: interpersonal networks are argued to mediate between various forms of social stress and health (Wilkinson, 2004). Several studies have investigated conditions for good personal and social development at this age (Lerner, \& Steinberg, 2004; Piko, \& Hamvai, 2010; Ikiz, \& Cakar, 2010). Relationships in the family (Nishikawa, Sundbom, \& Hägglöf, 2010; Bonino, 2001) and with the peer group (Cattellino, 2000) have a great influence on well-being and life satisfaction even in later times, as does social support, which is correlated with life satisfaction and self-esteem (Gallagher, \& Vella-Brodrick, 2008). During adolescence there is a greater investment in relationships with peers and a reduction in the time spent with parents (Allen, Insabella, Porter, Smith, Land, \& Phillips, 2006). However, the family retains its position as an important agent of socialization, covering the educational task in a less directive way (Hair, Moore, Garrett, Ling, \& Cleveland, 2008). Socialization during adolescence is a key process in developing social skills and successful ways of adaptation (Karademas, Peppa, Fotiou, \& Kokkevi, 2008; Van Ryzin, Gravely, \& Roseth, 2009).

Social support assumes a specific function for immigrants: it acts as a coping strategy to prevent negative mental health in the face of perceived discrimination (Brondolo, ver Halen, Pencille, Beatty, \& Contrada, 2009; Chou, 2012; Manetti, Zini, \& Cardinali, 2009), as happens with emotional support (Jackson, Williams, \& Torres, 2003). Moreover, strong instrumental support is negatively associated with depressive symptoms and mitigates the impact of perceived racial discrimination on depressive symptoms (Ajrouch, Reisine, Lim, Sohn, \& Ismail, 2010). On the other hand, some studies show that social network composition and frequency of support-seeking do not moderate the effect of perceived discrimination on psychological well-being (Fischer, \& Shaw, 1999; Thompson, 2006).

The successful development of resources and strengths during adolescence is related to the adoption of pro-social behaviour (Bandura, Caprara, Barbaranelli, Gerbino, \& Pastorelli, 2003; Damon, \& Gregory, 2003) academic achievement (Caprara, Barbaranelli, Pastorelli, \& Cervone, 2004) and prevention of depression and dysfunctional management of problems and behaviours (Caprara, Regalia, \& Bandura, 2002).

Self-efficacy beliefs are among the knowledge structures that have a pervasive influence on youths' positive development (Vecchio, Gerbino, Pastorelli, Del Bove, \& Caprara, 2007): self-efficacy is one's own ability to carry out actions achieving the desired result (Bandura, 1986). Bandura (1977) identifies some criteria to develop self-efficacy: past performance, vicarious experience and social observation, communicative persuasion, emotional and physiological state.

Past experiences of good performance can help the adolescent to become self-confident in similar activities: such tasks should not be too simple so as not to generate an overestimation of abilities, but neither too hard so as not to discourage a person faced with repeated failures. The subject can identify himself with other people who are similar to him and who have successfully overcome tasks, so becoming a model: this process is defined as vicarious experience. Communicative persuasion is a way to support 
the person in believing in his own abilities when challenged with real opportunities for success. The emotional states and physiological levels of stress and anxiety experienced influence the perception of Volume 1, 2012 a favourable climate and the opportunity to remedy mistakes in future experiences.

Longitudinal studies have confirmed that higher levels of self-efficacy (Bandura, 1996) are predictive of life satisfaction and family and social support, educational achievement and incomes (Torres, \& Solberg, 2001). Those individuals who are better at pursuing actions for change have a stronger self-efficacy. It is important to consider that actions are related not only to individuals but also to collective and social change (De Piccoli, 2007). Self-efficacy is mediated by the presence of support networks, and it is strictly conditioned by the system of values, socio-cultural variables (ethnicity, social class, education level, age, gender) and resources which are available within the social environment (Franzblau, \& Moore, 2001).

Self-efficacy, differently from self-esteem, which is a global measure of self-worth, is associated with specific areas and situations that regulate cognitive and motivational processes (Cattellino, 2000). In a multicultural background it is necessary to consider factors that affect intergroup contact and relationships among peers and with people who are ethnically diverse (Shellman, 2006; Briones, Tabernero, Tramontano, Caprara, \& Arenas, 2009; MacNab, \& Worthley, 2011). There are different perspectives of study: the role of social capital (Croninger, \& Lee, 2001), the conditions of intergroup contact (Pettigrew, \& Tropp, 2008), the development of cognitive functions that affect the management of interpersonal relationships in multicultural contexts (Bennett, 2004). Some researches investigate how the social and relational nature of self-efficacy influence the management of multicultural contexts: self-efficacy, especially in social relations, is significantly and positively correlated with social integration; low self-efficacy can affect the integration of immigrants (Schwarzer, \& Scholz, 2000; Briones, Tabernero, \& Arenas, 2005; Piontkowski, Florack, Hoelker, \& Obdrzalek, 2000) and it may be that a lack of integration could result in a loss of self-efficacy (De Saissy, 2009). Students with greater cross-cultural self-efficacy are more willing to mix with students from the host society (Fan, \& Mak, 1998) and several studies have confirmed that cross-cultural self-efficacy has a positive influence on relationships with people from other backgrounds (Briones et al., 2009; Bandura, 2006; Hechanova-Alampay, Beehr, Christiansen, \& Van Horn, 2002; Li, \& Gasser, 2005; Tsang, 2001).

Earley and Ang (2003) define cultural competence as a set of behaviours and congruent attitudes that allow people to function effectively in intercultural situations. They identified different kinds of strategies as factors which characterize cultural competence:

- strategies of meta-cognition come into play when the awareness of intercultural experiences and processes is used to acquire and understand cultural knowledge and information;

- knowledge: understanding cultures in their similarities and differences;

- motivational factors: people's interest in experiencing other cultures and meeting people belonging to different cultures;

- behaviour factors: this refers to people's ability to adapt their verbal and non-verbal behaviour to different contexts and interactions.

According to this study, Briones and colleagues (2009) validated a scale with young people in educational environments characterized by cultural diversity to measure how adolescents perceive their effectiveness in these areas.

This research wants to investigate the role of cultural self-efficacy with the purpose to understand its relevance in adolescent adjustment, and to develop suggestions about how the perception of specific cultural competences could affect intergroup contact through direct or vicarious experience.

\section{Methodology of Research}

\section{General Background of Research}

The purpose of this study is to investigate the relationships among well-being, self-esteem, social support and cultural self-efficacy in a group of Italian and immigrant adolescents attending secondary school. 
OF PSYCHOLOGY

IN THE $21^{\text {st }}$ CENTURY Volume 1, 2012

62

On the basis of review of the current research, this study seeks to validate the following hypotheses:

H1: Immigrant adolescents are expected to submit higher scores than Italians in cultural self-efficacy competences, for living a direct experience of change in the socio-cultural context (Bandura, 1977, 2006).

$\mathrm{H} 2$ : Cultural self-efficacy correlates with the immigrants' cultural adjustment (Briones et al., 2009);

H3: There is a relationship between intergroup friendships and Italians' cultural selfefficacy. Furthermore, we expect to find significant differences in self-esteem between those who choose intergroup friendships and those who don't (Vervoort et al., 2011).

\section{Sample of Research}

Participants are adolescents attending secondary school who are available and interested in taking part in research (convenience sample). There were 312, and the average age was 15 years old (54\% female). $79.5 \%$ of the participants were Italians, $10.9 \%$ were from Eastern Europe, $4.17 \%$ were from North Africa, $3.53 \%$ were from South America, and 1.90\% were of other origin.

Furthermore, 19 adolescents of double heritage participated in the data collection, but we excluded this group from the analysis owing to their relatively small number.

\section{Instrument and Procedures}

The participants were recruited from three secondary schools in a small city in the North of Italy. The data collection procedure complied with the Research Ethical Code of the Italian Association of Psychology: the informed consent protocol was provided to the students while presenting the aims of the research and before they started filling in the questionnaire. Students were correctly and clearly informed about all the aspects of the research that might have induced them to not provide their informed consent. Students were reassured that their answers would remain anonymous, in compliance with Italian Law on Privacy n.196/2003, and that they would be aggregated with those of the other students, processed for statistical calculations and presented as a whole.

Students were allowed to ask for clarification concerning questions and the researcher answered. The survey operations took place between October 2010 and March 2011. The self-report questionnaire included the following measures:

- Socio-demographic data schedule.

- Psychological Well-Being scales for adolescents (PWB) (Ryff, \& Keyes, 1995; Italian version modified for adolescence by Ruini, Belaise, Ottolini, Tomba, Caffo, \& Fava 2007). The scale consisted of six dimensions of psychological well-being: self-acceptance (e.g. when I compare myself with my friends and family I am satisfied with what I am), positive relations with others (e.g. I think that other people often have more friends than me), autonomy (e.g. sometimes I change the way I do things or my way of thinking, so I can be like other people), environmental mastery (e.g. I don't feel good with the people and the environment surrounding me), purpose in life (e.g. I feel good when I think about what I do and what I hope to do in the future) and personal development (e.g. I think it's important to have new experiences that change the way I see myself and the surrounding world). The respondents assess their personal agreement with the statements on a Likerttype scale ranging from $1=$ strongly disagree to $6=$ strongly agree.

- The Rosenberg Self-Esteem Scale (RSES) (Rosenberg, 1965) monitors global self-esteem (GSE) as one factor. The respondents assess their personal agreement with the statements on a Likert-type scale ranging from $1=$ strongly disagree to $4=$ strongly agree.

- The Multidimensional Scale of Perceived Social Support (MSPSS) (Zimet, Dahlen, Zimet, $\&$ Farley, 1988) is a 12-item scale that measures perceived support from three domains: family, friends, and a significant other. Participants completing the MSPSS are asked to 
indicate their agreement with items on a 5-point Likert-type scale, ranging from $1=$ very strongly disagree to $5=$ very strongly agree.

- Cultural Self-Efficacy Scale for Adolescents (CSES-A), (Briones, Tabernero, Tramontano, Caprara, \& Arena, 2009). Participants answered using a 5-point Likert scale (1 = very low level of knowledge; 5 = very high level of knowledge).

- The five factors identified in the CSES-A are defined as follows: self-efficacy in mixing satisfactorily with other cultures (Mix, e.g. Take part in social activities of the people of that culture), self-efficacy in understanding other ways of life (Understand, e.g. Understand other religious beliefs), self-efficacy in coping with homesickness and separation (Cope, e.g. Overcome nostalgia for my friends), self-efficacy in processing information about other cultures (Process, e.g. Use the information I have on that culture to understand people from that culture), self-efficacy in learning and understanding a foreign language (Language, e.g. Speak a language different from mine).

\section{Data Analysis}

All the data were stored in a computerized database and analysed with the aid of the Statistical Package for the Social Sciences (SPSS ver. 16.0.2; 2008).

Measures of the central tendency and distribution of variables were examined, and then it was conducted a $t$ Test to verify differences between Italian and immigrant groups, and Pearson's productmoment correlations of the key variables to help clarify the relationships between constructs under study and adolescents' adjustment.

\section{Results of Research}

Table 1 presents the Cronbach's $\alpha$ (alpha), means, standard deviations, minimum and maximum for all the variables.

All measures present a good internal consistency and scores higher than the theoretical mean.

Table 1. Descriptive statistics of constructs under study.

\begin{tabular}{ccccc}
\hline Scale & PWB & GSES & MSPSS & $\begin{array}{c}\text { Cultural Self-Efficacy } \\
\text { Scale for Adolescents } \\
\text { (CSES-A) }\end{array}$ \\
\hline $\begin{array}{cccc}\text { Mean } \\
\text { D.S. }\end{array}$ & 0.73 & 0.78 & 0.83 & 0.90 \\
Min. & 0.48 & 3.27 & 4.20 & 3.55 \\
Max. & 1 & 0.46 & 0.60 & 0.64 \\
\hline
\end{tabular}

H1: Immigrant adolescents are expected to submit higher scores than Italians in cultural self-efficacy competences.

To test the hypothesis regarding differences between immigrant and Italian students in cultural self-efficacy scores a $t$ Test for independent samples was conducted.

The results reported in Table 2 revealed that there are statistically significant differences between Italian and immigrant adolescents in all cultural self-efficacy dimensions and according to our hypothesis immigrant people obtain higher scores. The highest difference is in the capability to mix satisfactorily with other cultures (Mix). 
Table 2. Comparison between Italian and immigrant adolescents in cultural selfefficacy scores.

\begin{tabular}{|c|c|c|c|c|c|c|}
\hline & Group & $\mathbf{N}$ & Mean & df & $t$ & $\begin{array}{c}\text { Sig. } \\
\text { (2-tailed) }\end{array}$ \\
\hline \multirow{2}{*}{ Mix } & Italian & 240 & 3.72 & \multirow{2}{*}{298} & \multirow{2}{*}{-3.86} & \multirow{2}{*}{0.00} \\
\hline & Immigrant & 60 & 4.11 & & & \\
\hline \multirow{2}{*}{ Understand } & Italian & 245 & 3.34 & \multirow{2}{*}{303} & \multirow{2}{*}{-1.68} & \multirow{2}{*}{0.09} \\
\hline & Immigrant & 60 & 3.56 & & & \\
\hline \multirow{2}{*}{ Cope } & Italian & 244 & 2.90 & \multirow{2}{*}{298} & \multirow{2}{*}{-2.64} & \multirow{2}{*}{0.01} \\
\hline & Immigrant & 56 & 3.34 & & & \\
\hline \multirow{2}{*}{ Process } & Italian & 236 & 3.63 & \multirow{2}{*}{135.53} & \multirow{2}{*}{-2.44} & \multirow{2}{*}{0.02} \\
\hline & immigrant & 62 & 3.85 & & & \\
\hline \multirow{2}{*}{ Language } & Italian & 245 & 3.79 & \multirow{2}{*}{304} & \multirow{2}{*}{-3.68} & \multirow{2}{*}{0.00} \\
\hline & Immigrant & 61 & 4.30 & & & \\
\hline \multirow{2}{*}{ CSES-A Total } & Italian & 227 & 3.49 & \multirow{2}{*}{275} & \multirow{2}{*}{-3.352} & \multirow{2}{*}{0.001} \\
\hline & Immigrant & 50 & 3.82 & & & \\
\hline
\end{tabular}

Student $t$ Test $p<0.01$

\section{H2: Cultural self-efficacy correlates with the immigrants' cultural adjustment}

Pearson's product-moment correlations were calculated to assess the relationship among cultural self-efficacy dimensions and well-being, self-esteem, social support (from family, friends, special person) separately in the Italian and immigrant groups.

For Italian adolescents well-being correlates with self-esteem $(r=0.653 ; p<0.01)$ and with all the dimensions of social support (special person $r=0.246 ; p<0.01$; friends support $r=0.194 ; p<0.01$; family support $r=0.266 ; p<0.01$ ).

In Table 3 we can observe a significant relationship between the cultural self-efficacy total score and family support $(r=0.271 ; p<0.01)$. Perceived support from a special person correlates with some dimensions of cultural self-efficacy but not with the total scores. In particular, there is a small relationship between support from a special person and the effectiveness in using information in a different cultural context (Process) $(r=0.199 ; p<0.01)$, in mixing with people from other cultural contexts (Mix) $(r=0.144 ; p<0.05)$, in understanding different lifestyles (Understand) $(r=0.195$; $p<0.01)$ and in understanding a foreign language (Language) $(r=0.147 ; p<0.05)$.

As concerns immigrant adolescents, we can see in Table 3 the existence of significant positive correlations between well-being and self-esteem $(r=0.725 ; p<0.01)$ also for this group.

Table 3. Correlation among variables in Italians and immigrants adolescent.

\begin{tabular}{|c|c|c|c|c|c|c|c|}
\hline $\begin{array}{c}\text { Italians } \\
\text { Immigrants }\end{array}$ & & $\begin{array}{c}\text { Well-being } \\
\text { Total } \\
\text { Score }\end{array}$ & Self-Esteem & $\begin{array}{l}\text { Special } \\
\text { Person } \\
\text { Support }\end{array}$ & $\begin{array}{l}\text { Friends } \\
\text { Support }\end{array}$ & $\begin{array}{l}\text { Family } \\
\text { Support }\end{array}$ & $\begin{array}{l}\text { CSES-A } \\
\text { Total Score }\end{array}$ \\
\hline \multicolumn{8}{|c|}{ Italians } \\
\hline $\begin{array}{l}\text { Well-being Total } \\
\text { Score }\end{array}$ & Immigrants & 1 & $\left.0.6533^{* *}\right)$ & $0.246\left(^{* *}\right)$ & $\left.0.1944^{* *}\right)$ & $0.266\left({ }^{* *}\right)$ & -0.002 \\
\hline Self Esteem & & $\left.0.7255^{* *}\right)$ & 1 & 0.123 & 0.115 & $0.264\left(^{* *}\right)$ & -0.053 \\
\hline
\end{tabular}




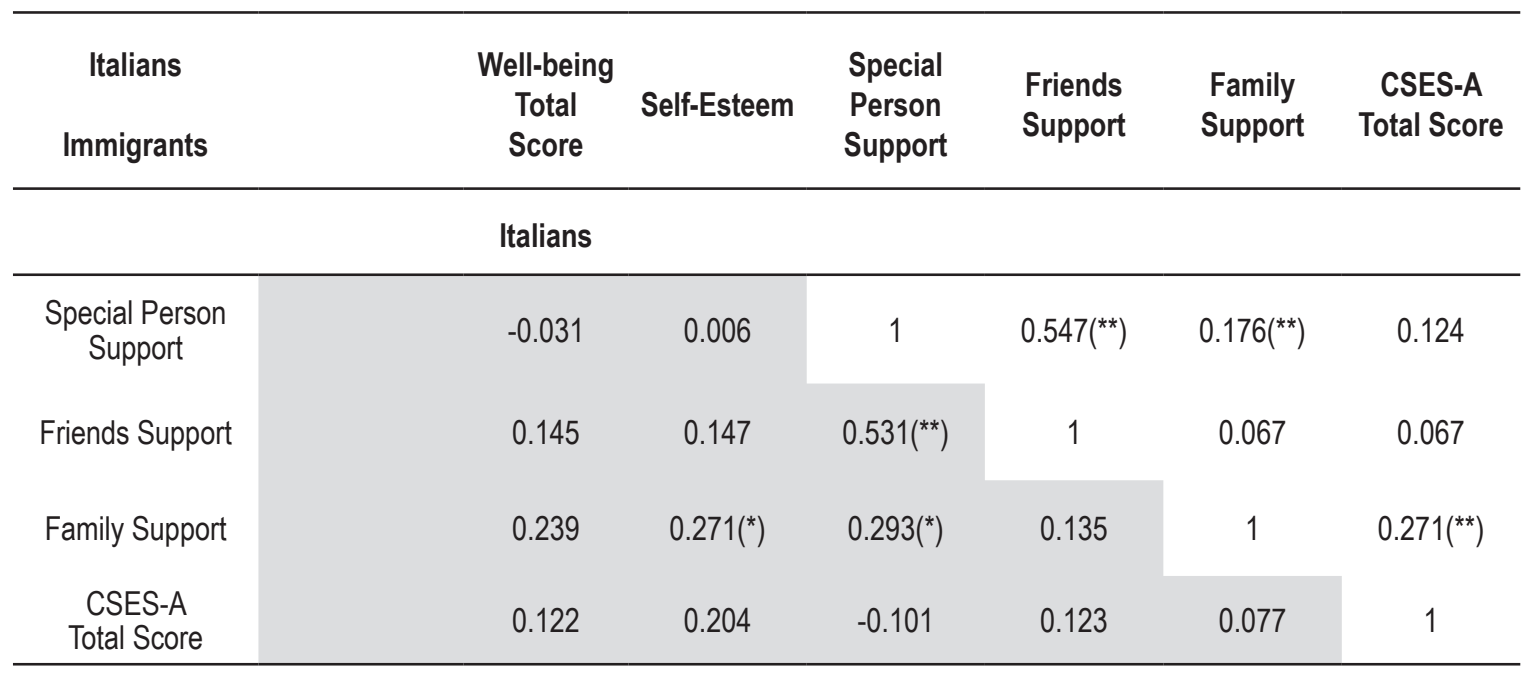

Pearson Correlation ${ }^{* *} p<0.01 ;{ }^{*} p<0.05$

Furthermore, self-esteem correlates with family support $(r=0.271, p<0.05)$. The special person support is correlated with friends support $(r=0.531, p<0.01)$ and family support $(r=0.293, p$ $<0.05$ ), but there are no relationships between friends and family supports.

Looking at the cultural dimension of self-efficacy, there is an inverse correlation between selfefficacy in dealing with separation (Cope) and the support perceived from a special person $(r=-0.279$, $p<0.05)$ and a positive relationship between the same dimension of self-efficacy and self-esteem $(r$ $=0.303, p<0.05)$, but the CSES-A total scores do not correlate with other constructs.

H3: There is a relationship between intergroup friendships and Italians'cultural selfefficacy. Furthermore, we expect to find significant differences in self-esteem between those who choose intergroup friendships and those who don't.

Cultural self-efficacy was explored in the Italian participants group, dividing it into two subgroups: those who choose as friends only Italian adolescents and those who choose both Italians and foreign friends (intercultural friendship).

Data analysis clearly indicate a higher level of cultural self-efficacy among young Italians who claim to have both Italian and foreign friends (Tab. 4). Only in self-efficacy in coping with homesickness and separation (Cope) is there no statistically significant difference between the two groups.

Table 4. Comparison between cultural self-efficacy scores of Italian adolescents with and without intergroup friendships.

\begin{tabular}{|c|c|c|c|c|c|c|}
\hline & Groups & $\mathbf{N}$ & Mean & df & $t$ & $\begin{array}{c}\text { Sig. } \\
\text { (2-tailed) }\end{array}$ \\
\hline \multirow{2}{*}{ Mix } & Only Italian friends & 75 & 3.39 & \multirow{2}{*}{100.26} & \multirow{2}{*}{-3.97} & \multirow{2}{*}{0.00} \\
\hline & Italian and foreign friends & 164 & 3.86 & & & \\
\hline \multirow{2}{*}{ Understand } & Only Italian friends & 77 & 2.96 & \multirow{2}{*}{120.23} & \multirow{2}{*}{-4.31} & \multirow{2}{*}{0.00} \\
\hline & Italian and foreign friends & 166 & 3.52 & & & \\
\hline \multirow{2}{*}{ Cope } & Only Italian friends & 75 & 2.78 & \multirow{2}{*}{131.48} & \multirow{2}{*}{-1.05} & \multirow{2}{*}{0.30} \\
\hline & Italian and foreign friends & 168 & 2.95 & & & \\
\hline \multirow{2}{*}{ Process } & Only Italian friends & 72 & 3.22 & \multirow{2}{*}{107.28} & \multirow{2}{*}{-4.53} & \multirow{2}{*}{0.00} \\
\hline & Italian and foreign friends & 163 & 3.80 & & & \\
\hline
\end{tabular}




\begin{tabular}{|c|c|c|c|c|c|c|}
\hline & Groups & N & Mean & df & $t$ & $\begin{array}{c}\text { Sig. } \\
\text { (2-tailed) }\end{array}$ \\
\hline \multirow{2}{*}{ Language } & Only Italian friends & 77 & 3.52 & \multirow{2}{*}{121.87} & \multirow{2}{*}{-2.59} & \multirow{2}{*}{0.01} \\
\hline & Italian and foreign friends & 166 & 3.90 & & & \\
\hline \multirow{2}{*}{ CSES-A Total } & Only Italian friends & 68 & 3.19 & \multirow{2}{*}{93.353} & \multirow{2}{*}{-4.137} & \multirow{2}{*}{0.000} \\
\hline & Italian and foreign friends & 158 & 3.62 & & & \\
\hline \multirow{2}{*}{ Self-esteem } & Only Italian friends & 78 & 33.85 & \multirow{2}{*}{138.10} & \multirow{2}{*}{2.01} & \multirow{2}{*}{0.046} \\
\hline & Italian and foreign friends & 165 & 32.58 & & & \\
\hline
\end{tabular}

Student $t$ Test $p<0.05$

Furthermore, adolescents who have only friends belonging to their in-group show significantly higher self-esteem scores than their peers who are open to intergroup relations $(t=2.01$; $p<0.05)$.

\section{Discussion}

The construct of self-efficacy has been receiving growing attention in educational research, especially examining its influence on motivation and learning (Van Dinther, Dochy, \& Segers, 2011). The analysis shows that immigrant adolescents have higher scores for cultural self-efficacy than Italians of the same age. Hypothesis H1 can be considered confirmed, suggesting that direct experience of management of a migratory track (Briones et al., 2009; Bandura, 1996) and encounters with another social context, encourage them to face the challenges of cultural or language adaptation through the activation of resources and increasing the perception of one's cultural self-efficacy (Bandura, 2006).

Despite this, in the immigrants group cultural self-efficacy does not correlate with overall dimensions of adjustment (disconfirmation of Hypothesis H2); this finding is not consistent with previous studies that conceived that low self-efficacy would adversely affect the integration of immigrants through the discouragement of social interaction with the dominant group. For Italian participants, cultural self-efficacy seems to be significantly correlated with family support, but this is not the case for immigrant adolescents: there are probably other dimensions of adjustment that are more relevant to an adolescent's cultural self-efficacy than the constructs available from the data. A possible explanation is that when adolescents directly experience migration, intimate relations that provide support, like the family, lose their influence or change: a distance between adolescents and parents on cultural values is part of the normal developmental process in immigrant families (Sam, \& Virta, 2003) and can be a source of development (Rosenthal, \& Hrynevich, 1985).

Probably other factors, such as acculturation stress, could help to explain this condition (Briones et al., 2009). Furthermore, in our study we have not considered socio-cultural variables that influence value and the emotional significance of immigrants' social identity. Social hostility could negatively correlate with self-efficacy and well-being (De Saissy, 2009).

Hypothesis $\mathrm{H} 3$ has been confirmed, because cultural self-efficacy scores are higher in Italian adolescents who maintain intergroup friendships: consistent with Vervoort et al.'s (2011) hypothesis, self-esteem assumes a different value related to the intergroup friendship chosen. Those who prefer to have friends from the same cultural group seem to have higher self-esteem: this could be explained by the characteristics of the socio-cultural context, which probably does not support intercultural competences to promote intergroup relations: the region where the research took place is characterised by conservative politics on migration and cultural maintenance.

People open to cultural change could have more occasion to develop and experience good inter-ethnic contact (Franzblau, \& Moore, 2001; De Piccoli, 2007). The ethnic composition of the schools or neighbourhoods may also play a role in determining the availability of potential 
friends from a different ethnic group (Smith, \& Schneider, 2000), maintaining those conditions necessary for a good intergroup contact: equal status, cooperation, common goals and institutional Volume 1, 2012 support (Pettigrew, 1997). Researchers identified as protective factors of migration the ability to adapt in a changing environment, language knowledge and the presence of a supportive social network (Prilleltensky, \& Arcidiacono, 2010). The multi-ethnic environment can stimulate in adolescents the improvement of social skills in contact with other cultures (Briones et al., 2009; Bandura, 2006).

In the Italian group cultural self-efficacy seems to be associated with intimate relationships. This finding points towards intercultural contact as a potentially important aspect in the development of cultural self-efficacy. In order to clarify better how to handle intercultural contact as a source of friendship and cultural self-efficacy development, it would be necessary to deepen the relationship with friend support, which is marginal in our results. However, more experimental approaches could be developed to supplement the current findings.

Further analyses should consider also gender, specific group ethnicity, age, duration of residency, and acculturation as potential contributors to the variance in the cultural self-efficacy scores. Despite these limitations, our results are interesting because they provide some grounds for fostering the assumption that intercultural experiences (like migration or intercultural friendship) could improve cultural self-efficacy.

\section{Conclusions}

The realization of a peaceful and harmonious coexistence in a globalized world suggests the need to expand studies related to the acquisition of language, and behavioural and motivational skills in intercultural contacts in both minority and in majority groups. Educational programs which improve language skills and competences through peer education could improve natives' cultural self-efficacy in their contact with migrants' enactive mastery experiences. Contexts such as the school in which the contact takes place hold an important role in promoting adolescents' skills and providing opportunities for the consolidation of wealth and perceptions of self-efficacy. Adolescents who have overcome successfully the obstacles of a changing socio-cultural environment could become good models for vicarious experience of Italians of the same age who are trying to learn a different language or mix with people from different cultural backgrounds. A supportive school environment can sustain listening among students and constructive meeting of the differences.

The process of transition involved in immigration has been described as a potentially positive experience, representing the opportunity for personal growth and self-development. In fact, migration experience could be considered as an opportunity to enhance cultural competence and skills.

It is useful to consider the opportunity to create a framework for meeting and learning in line with the proposal in Bandura's social learning theory: young immigrants could benefit from a positive acknowledgement of their cultural competences and adaptation to a new socio-cultural context.

\section{Acknowledgements}

This research was supported by University of Genoa. We thank teachers and adolescents of the schools involved for their important contribution to the development of the research.

\section{References}

Allen, J. P., Insabella, G., Porter, M. R., Smith, F. D., Land, D., \& Phillips, N. (2006). A social interactional model of the development of depressive symptoms in adolescence. Journal of Consulting and Clinical Psychology, 74 (1), 55-65. 
OF PSYCHOLOGY

IN THE $21^{\text {st }}$ CENTURY Volume 1, 2012

Allport, G. W. (1954). The nature of prejudice. Cambridge: Addison-Wesley.

Ajrouch, K. J., Reisine, S., Lim, S., Sohn, W., \& Ismail, A. (2010). Perceived everyday discrimination and psychological distress: does social support matter? Ethnicity \& Health, 15, 417-434.

Bandura, A. (1986). Social foundations of thought and action: A social cognitive theory, Englewood Cliffs, NJ: Prentice-Hall.

Bandura, A. (1977). Self-efficacy: toward a unifying theory of behavioral change. Psychological Review, 84 ( 2), 191-215.

Bandura, A. (1996). Il senso di autoefficacia. Trento: Centro Studi Erickson. (original ed., 1995). Self-efficacy in changing societies. Cambridge: Cambridge University Press (Italian translation)

Bandura, A., Caprara, G. V., Barbaranelli, C., Gerbino, M., \& Pastorelli, C. (2003). Role of affective self-regulatory efficacy in diverse spheres of psychosocial functioning. Child Development, 74, 769-782.

Bandura, A. (2006). Adolescent development from an agentic perspective. In Pajares, F., \& Urdan, T. (Eds.), Self-efficacy beliefs of adolescents (Vol. 5, pp. 1-43). Greenwich, CT: Information Age Publishing.

Beiser, M. (1990). Migration: Opportunity or mental health risk. Triangle, 29 (2/3), 83-90.

Bennett, M. J. (2004). Becoming interculturally competent. In Wurzel, J. (Ed.), Toward multiculturalism: A reader in multicultural education (2nd ed., pp. 62-77). Newton, MA: Intercultural Resource Corporation.

Bonino, S. (2001). Nucleo monotematico: La famiglia e il benessere degli adolescenti. Età evolutiva, 69, 43-94.

Briones, E., Tabernero, C., Arenas, A. (2005). Variables psicosociales relacionadas con el proceso de integracio'n social de los estudiantes inmigrantes. Cultura y Educación, 17 (4), 337-347.

Briones, E., Tabernero, C., Tramontano, C., Caprara, G. V., \& Arenas, A. (2009). Development of a cultural self-efficacy scale for adolescents (CSES-A). International Journal of Intercultural Relations, 33, 301-312.

Brondolo, E., ver Halen, N. B., Pencille, M., Beatty, D., \& Contrada, R. J. (2009). Coping with racism: a selective review of the literature and a theoretical and methodological critique. Journal of Behavioral Medicine, 32, 64-88.

Caprara, G. V., Regalia, C., \& Bandura, A. (2002). Longitudinal impact of perceived self-regulatory efficacy on violent conduct. European Psychologist, 7, 63-69.

Caprara, G. V., Barbaranelli, C., Pastorelli, C., \& Cervone, D. (2004). The contribution of self-referent beliefs to personality development. Perceived self-efficacy and Big Five constructs as predictors of psychosocial outcomes. Personality and Individual differences, 37, 751-763.

Cattellino, E. (2000). Adolescenti tra rischio e benessere: il contributo dell' autoefficacia scolastica. L'École Valdotaine, 45, 13-17.

Chou, K.-L. (2012). Perceived discrimination and depression among new migrants to Hong Kong: The moderating role of social support and neighborhood collective efficacy. Journal of Affective Disorders, doi:10.1016/j.jad.2011.12.029

Croninger, R. G., \& Lee, V.E. (2001). Social capital and dropping out of high school. Benefits to at-risk students of teachers' support and guidance. Teachers College Record, 103, 548-581.

Damon, W., \& Gregory, A. (2003). Bringing in a new era in the field of youth development. In Lerner, R. M., \& Benson, P. L. (Eds.), Developmental assets and asset-building communities: Implications for research, policy, and practice (pp. 47-64). Norwell, MA: Kluwer Academic.

De Piccoli, N. (2007). Individui e contesti in psicologia di comunità. Milan: Ed. Unicopli.

De Saissy, C. K. M. (2009). Acculturation, self-efficacy and social support among Chinese immigrants in Northern Ireland. International Journal of Intercultural Relations, 33, 291-300.

Earley, P. C., \& Ang, S. (2003). Cultural intelligence: Individual interactions across cultures. Palo Alto: Stanford University Press.

Fan, C., \& Mak, A. S. (1998), Measuring social self-efficacy in a culturally diverse student population. Social Behavior and Personality, 26 (2), 131-144. 
Fischer, A. R., \& Shaw, C. M. (1999). African Americans' mental health and perceptions of racist discrimination: the moderating effects of racial socialization experiences and self-esteem. Journal of Counseling Volume 1, 2012 Psychology, 46, 395-407.

Franzblau, S. H., \& Moore, M. (2001). Socializing efficacy: A reconstruction of self-efficacy theory within the context of inequality. Journal of Community and Applied Social Psychology, 11, 83-96.

Gallagher, E. N., \& Vella-Brodrick, D. A. (2008). Social support and emotional intelligence as predictors of subjective well-being, Personality and Individual Differences, 44, 1551-1561.

Hair, E. C., Moore, K. A., Garrett, S. B., Ling, T., \& Cleveland, K. (2008). The continued importance of quality parent-adolescent relationships during late adolescence. Journal of Research on Adolescence, 8, 187-200.

Hechanova-Alampay, R., Beehr, T. A., Christiansen, N. D., \& Van Horn, R. K. (2002). Adjustment and strain among domestic and international student sojourners: A longitudinal study. School Psychology International, 23, 458-474.

Ikiz, F. E., \& Cakar, F. S. (2010). Perceived social support and self-esteem in adolescence. Procedia Social and Behavioral Sciences, 5, 2338-2342.

Jackson, J. S., Williams, D. R., \& Torres, M. (2003). Perceptions of discrimination, health and mental health: the social stress process. In Maney, A., \& Ramos, J. (Eds.), Socioeconomic conditions, stress and mental disorders: toward a new synthesis of research and public policy. (http://www.mhsip.org/ nimhdoc/socioeconmh_home2.htm (chapter 8)).

Karademas, E. C., Peppa, N., Fotiou, A., \& Kokkevi, A. (2008). Family, school and health in children and adolescents. Journal of Health Psychology, 3, 1012-1020.

Klimidis, S., Stuart, G., Minas, I. H., \& Ata, A. W. (1994). Immigrant status and gender effects on psychopathology and self-concept in adolescents: A test of the migration morbidity hypothesis. Comprehensive Psychiatry, 35(5), 393-404.

Kroger, J. (2000). Identity development: Adolescence through adulthood. Thousand Oaks, CA: Sage.

Lerner, R. M., \& Steinberg, L. (Eds.). (2004). Handbook of adolescent psychology (2nd ed.). Hoboken, NJ: John Wiley \& Sons.

Li, A., \& Gasser, M. B. (2005). Predicting Asian international students' sociocultural adjustment: A test of two mediation models. International Journal of Intercultural Relations, 29, 561-576.

MacNab, B. R., \& Worthley, R. (2011). Individual characteristics as predictors of cultural intelligence development: The relevance of self-efficacy. International Journal of Intercultural Relations, doi:10.1016/j. ijintrel.2010.12.001

Manetti, M., Zini, E., \& Cardinali, P. (2009). Processi di accomodamento intersistemico nelle relazioni scuola famiglia: la funzione dei supporti nella costruzione del benessere di adolescenti italiani e immigrati. Rivista di psicologia di comunità, Numero monografico: Modello ecologico e migrazioni 1, 63-72.

Mirsky, J. (1997). Psychological distress among immigrant adolescents: Culture specific factors in the case of immigrant adolescents from the former Soviet Union. International Journal of Psychology, 32, 221-230.

Nishikawa, S., Sundbom, E., \& Hägglöf, B. (2010). Influence of perceived parental rearing on adolescent self-concept and internalizing and externalizing problems in Japan. Journal of Child Family Studies, 19 (1), 57-66.

Palmonari, A., Pombeni, M. L., \& Kirchler, E. (1990). Adolescents and their peer groups: a study on the significance of peers, social categorization processes and coping with developmental tasks. Social Behaviour, 5, 33-48.

Pettigrew, T. F. (1997). Generalized intergroup contact effects on prejudice. Personality and Social Psychology Bulletin, 23, 173-185.

Pettigrew, T. F., \& Tropp, L. R. (2008). How does intergroup contact reduce prejudice? Meta-analytic tests of three mediators. European Journal of Social Psychology, 38, 922-934.

Phinney, J. S. (1991). Ethnic identity and self-esteem: a review and integration. Hispanic Journal of Behavioral Sciences, 13, 193-208. 
Piko, B. F., \& Hamvai, C. (2010). Parent, school and peer-related correlates of adolescents' life satisfaction. Children and Youth Services Review, 32, 1479-1482.

Piontkowski, U., Florack, A., Hoelker, P., \& Obdrzalek, P. (2000). Predicting acculturation attitudes of dominant and non-dominant groups. International Journal of Intercultural Relations, 24, 1-26.

Prilleltensky, I., \& Arcidiacono, C. (2010). Modello ecologico e migranti: benessere, giustizia e potere nella vita degli immigrati. Psicologia di Comunità, 1, 11-23

Rosenberg, M. (1965). Society and the adolescent self-image. Princeton, NJ: Princeton University Press.

Rosenthal, D. A., \& Hrynevich, C. (1985). Ethnicity and ethnic identity: A comparative study of Greek-, Italian-, and Anglo-Australian adolescents. International Journal of Psychology, 20 (6), 723-742.

Ruini, C., Belaise, C., Ottolini, F., Tomba, E., Caffo, E., \& Fava, G. A. (2007). L'applicazione della WellBeing Therapy in ambito scolastico: uno studio pilota. Rivista di Psichiatria, 42, 320-326.

Ryff, C. D., \& Keyes, C. L. (1995). The structure of psychological well-being revisited. Journal of Personality and Social Psychology, 69 (4), 719-27.

Sabatier, C. (2008). Ethnic and national identity among second-generation immigrant adolescents in France: The role of social context and family. Journal of Adolescence, 31, 185-205.

Sam, D. L., \& Virta, E. (2003). Intergenerational value discrepancies in immigrant and host-national families and their impact on psychological adaptation. Journal of Adolescence, 26(2), 213-231.

Schwarzer, R., \& Scholz, U. (2000). Cross-cultural assessment of coping resources: The general perceived self-efficacy scale. Paper presented at the Asian Congress of Health Psychology 2000: Health Psychology and Culture, Tokyo, August 28-29, 2000. Retrieved November 16, 2005, from http://web. fu-berlin.de/gesund/publicat world_data.htm.

Scott, W., \& Scott, R. (1989). Adaptation of immigrants: Individual differences and determinants. Sydney, Australia: Pergamon Press.

Shellman, J. (2006). Development and psychometric evaluation of the Eldercare Cultural Self-Efficacy Scale. International Journal of Nursing Education Scholarship, 3 (1), Article 9.

Smith, A., \& Schneider, B. H. (2000). The inter-ethnic friendships of adolescent students: A Canadian study. International Journal of Intercultural Relations, 24, 247-258.

Tajfel, H., \& Turner, J. C. (1979). An integrative theory of intergroup conflict. In Austin, W. G., \& Worchel, S. (Eds.), The social psychology of intergroup relations (pp. 33-47). Monterey, CA: Brooks/Cole.

Thompson, V. L. S. (2006). Coping responses and the experience of discrimination. Journal of Applied Social Psychology, 36, 1198-1214.

Torres, J. B., \& Solberg, V. S. (2001). Role of self-efficacy, stress, social integration, and family support in Latino college student persistence and health. Journal of Vocational Behavior, 59 (1), 53-63.

Turner, R. N., Voci, A., \& Hewstone, M. (2007). Reducing explicit and implicit outgroup prejudice via direct and extended contact: the mediating role of self-disclosure and intergroup anxiety. Journal of Personality and Social Psychology, 93, 369-388.

Tsang, E. W. K. (2001). Adjustment of mainland Chinese academics and students to Singapore. International Journal of Intercultural Relations, 25, 347-372.

Van Dinther, M., Dochy, F., \& Segers, M. (2011). Factors affecting students' self-efficacy in higher education. Educational Research Review, 6, 95-108.

Van Ryzin, M. J., Gravely, A. A., \& Roseth, C. J. (2009). Autonomy, belongingness, and engagement in school as contributors to adolescent psychological well being. Journal of Youth and Adolescence, 38, 1-12.

Vecchio, G. M., Gerbino, M., Pastorelli, C., Del Bove, G., \& Caprara, G. V. (2007). Multi-faceted selfefficacy beliefs as predictors of life satisfaction in late adolescence. Personality and Individual Differences, 43, 1807-1818.

Vervoort, M. H. M., Scholte, R. H. J., \& Scheepers, P. L. H. (2011). Ethnic composition of school classes, majority-minority friendships, and adolescents' intergroup attitudes in the Netherlands. Journal of Adolescence, 34, 257-267. 
Walsh, S., Shulman, S., \& Maurer, O. (2008). Immigration distress, mental health status and coping among young immigrants: A 1-year follow-up study, International Journal of Intercultural Relations, 32 (5), 371-384.

Wilkinson, R. B. (2004). The role of parental and peer attachment in the psychological health and self-esteem of adolescents. Journal of Youth and Adolescence, 33(6), 479-493.

Zimet, G. D., Dahlem, N. W., Zimet, S. G., \& Farley, G. K. (1988). The Multidimensional Scale of Perceived Social Support. Journal of Personality Assessment, 52, 30-41.

Advised by Alessandra Fermani, University of Macerata, Italy

Received: January 25, 2012

Accepted: March 19, 2012

\begin{tabular}{cl}
\hline Nadia Rania & $\begin{array}{l}\text { Researcher, University of Genoa, C.so Podestà 2, 16100, Genoa, Italy. } \\
\text { E-mail: hadia.rania@uniqe.i. } \\
\text { Website: http://www.unige.it }\end{array}$ \\
\hline Paola Cardinali & $\begin{array}{l}\text { PhD, University of Genoa, C.so Podestà 2, 16100, Genoa, Italy. } \\
\text { E-mail: } \text { paola.cardinali@unige.it }\end{array}$ \\
\hline Chiara Cifatte & $\begin{array}{l}\text { PhD Student, University of Genoa, C.so Podestà 2, 16100, Genoa, Italy. } \\
\text { E-mail: Chiara.cifatte@unige.it }\end{array}$ \\
\hline \multirow{2}{*}{ Laura Migliorini } & $\begin{array}{l}\text { Associate Professor, University of Genoa, C.so Podestà 2, 16100, Genoa, Italy. } \\
\text { E-mail: Eura.migliorini@unige.it }\end{array}$ \\
\hline
\end{tabular}

